\title{
Extracellular vesicles from human liver stem cells restore argininosuccinate synthase deficiency
}

\author{
Maria Beatriz Herrera Sanchez ${ }^{1,2 \dagger}$, Sara Previdi ${ }^{3 \dagger}$, Stefania Bruno ${ }^{4}$, Valentina Fonsato ${ }^{1,2}$, Maria Chiara Deregibus ${ }^{1,2}$, \\ Sharad Kholia ${ }^{2}$, Sara Petrillo ${ }^{4}$, Emanuela Tolosano ${ }^{4}$, Rossana Critelli ${ }^{5}$, Marco Spada ${ }^{6}$, Renato Romagnoli ${ }^{7}$, \\ Mauro Salizzoni ${ }^{7}$, Ciro Tetta ${ }^{8}$ and Giovanni Camussi ${ }^{*^{*}}$
}

\begin{abstract}
Background: Argininosuccinate synthase (ASS)1 is a urea cycle enzyme that catalyzes the conversion of citrulline and aspartate to argininosuccinate. Mutations in the ASS1 gene cause citrullinemia type I, a rare autosomal recessive disorder characterized by neonatal hyperammonemia, elevated citrulline levels, and early neonatal death. Treatment for this disease is currently restricted to liver transplantation; however, due to limited organ availability, substitute therapies are required. Recently, extracellular vesicles (EVs) have been reported to act as intercellular transporters carrying genetic information responsible for cell reprogramming. In previous studies, we isolated a population of stem cell-like cells known as human liver stem cells (HLSCs) from healthy liver tissue. Moreover, EVs derived from HLSCs were reported to exhibit regenerative effects on the liver parenchyma in models of acute liver injury. The aim of this study was to evaluate whether EVs derived from normal HLSCs restored ASS1 enzymatic activity and urea production in hepatocytes differentiated from HLSCs derived from a patient with type I citrullinemia.
\end{abstract}

Methods: HLSCs were isolated from the liver of a patient with type I citrullinemia (ASS1-HLSCs) and characterized by fluorescence-activated cell sorting (FACS), immunofluorescence, and DNA sequencing analysis. Furthermore, their differentiation capabilities in vitro were also assessed. Hepatocytes differentiated from ASS1-HLSCs were evaluated by the production of urea and ASS enzymatic activity.

EVs derived from normal HLSCs were purified by differential ultracentrifugation followed by floating density gradient. The EV content was analyzed to identify the presence of ASS1 protein, mRNA, and ASS1 gene. In order to obtain ASS1-depleted EVs, a knockdown of the ASS1 gene in HLSCs was performed followed by EV isolation from these cells.

Results: Treating ASS1-HLSCS with EVs from HLSCS restored both ASS1 activity and urea production mainly through the transfer of ASS1 enzyme and mRNA. In fact, EVs from ASS1-knockdown HLSCs contained low amounts of ASS1 mRNA and protein, and were unable to restore urea production in hepatocytes differentiated from ASS1-HLSCS.

Conclusions: Collectively, these results suggest that EVs derived from normal HLSCs may compensate the loss of ASS1 enzyme activity in hepatocytes differentiated from ASS1-HLSCS.

Keywords: Liver transplantation, Citrullinemia type I, Stem cells, Extracellular vesicles

\footnotetext{
* Correspondence: giovanni.camussi@unito.it

${ }^{\dagger}$ Equal contributors

${ }^{9}$ Department of Medical Sciences, University of Torino, Corso Dogliotti 14,

I-10126 Torino, Italy

Full list of author information is available at the end of the article
} 


\section{Background}

Citrullinemia type I is an autosomal recessive disorder caused by a deficiency in argininosuccinate synthase (ASS; common gene symbol alias: ASS1), an enzyme that catalyzes the third reaction of the urea cycle [1]. Typical symptoms that characterize the disorder include hyperammonemia, low plasma arginine levels, and elevated levels of citrulline in the plasma and urine $[2,3]$. Furthermore, accumulation of ammonia during the first few days of life leads to poor feeding, vomiting, neuropsychiatric symptoms, and coma [2]. Current treatments involve pharmacologic nitrogen scavenger therapy, lifelong protein restriction, and L-arginine supplementation which are aimed towards symptomatic control. For patients that do not respond satisfactorily to these treatments the only alternative is liver transplantation. However, due to the limited availability of donor livers, alternative treatments such as gene therapy are currently under investigation [2].

Previously, we have isolated a population of stem celllike cells from the human liver known as human liver stem cells (HLSCs) which not only express liver tissuespecific markers, but also mesenchymal and embryonic stem cell markers $[4,5]$. Furthermore, under appropriate cell culture conditions, HLSCs demonstrate in vitro differentiation abilities as well as in vivo regenerative properties [4, 5]. For instance, under low gravity culture conditions in the presence of hepatocyte growth factor and fibroblast growth factor 4, HLSCs differentiate into mature hepatocytes [4].

Over the past decade, stem cells have been studied extensively as a form of therapy due to their healing ability. Several preclinical models have been developed out of which a paracrine mechanism of action has been suggested $[6,7]$. In the midst of various paracrine mediators identified, extracellular vesicles (EVs) have also been implicated to play a role in the exchange of information [8]. EVs are membrane bound particles secreted by cells in the extracellular milieu. They are classified into two main categories according to their size and subcellular origin. Exosomes are smaller in size (30-100 nm) and are released by exocytosis through the fusion of intracellular multivesicular bodies with the plasma membrane. Microvesicles, on the other hand, are larger (up to $1000 \mathrm{~nm}$ ) and are shed by direct budding from the cell plasma membrane [8]. Once secreted, these vesicles either remain in the extracellular matrix close to the cell of origin or disperse to other parts of the body through the blood or lymphatic system allowing intercellular exchange of proteins, bioactive lipids, and nucleic acids.

As intercellular vehicles, EVs carry a variety of cargo. For instance, Ratajczak et al. demonstrated that EVs derived from embryonic stem cells may contribute towards the reprogramming of hematopoietic progenitor cells through the delivery of embryonic stem cell-derived proteins and mRNA [9]. Subsequently, other studies followed this up that showed that EVs derived from adult cells also contained and transferred mRNAs and miRNAs to target cells $[10,11]$.

The ability of EVs to reprogram as a consequence of transferring RNAs has been demonstrated in different tissues and pathologies [12]. For instance, we observed that endothelial progenitor cell-derived EVs activated angiogenic pathways in recipient endothelial cells through horizontal transfer of mRNA [11]. Moreover, in different models of tissue injury, treatments with EVs derived from mesenchymal stem cells have been reported to promote tissue regeneration [13-16]. We also observed that the administration of EVs derived from HLSCs improved the regeneration of liver in rats with a $70 \%$ hepatectomy [17] and assisted in the overall recovery of mice in a murine model of acute kidney injury [18].

In this study, we investigated whether EVs derived from normal HLSCs had the ability to carry and transfer wild-type ASS1 to mature hepatocytes differentiated from ASS1-mutated HLSCs, thereby restoring enzyme activity and urea production.

\section{Methods \\ Isolation and culture of normal and mutated human liver stem cells}

A liver specimen from a 5-year-old citrullinemia type I patient undergoing liver transplant was obtained under written informed consent from the parents. The tissue was provided anonymously according to the local tissue banking protocol of discarded tissues (\# 80911) approved by the University of Torino Ethics Board (Comitato Bioetica di Ateneo).

Hepatocytes were isolated from the liver specimen (5$20 \mathrm{~g}$ ) by collagenase digestion following the same protocol as for the isolation of normal HLSCs as described previously [5]. Briefly, isolated liver tissues were digested in liver digest medium (Invitrogen, Carlsbad, CA, USA) at $37{ }^{\circ} \mathrm{C}$. The cell suspension obtained was filtered through a sterile $100-\mu \mathrm{m}$ nylon mesh, centrifuged at $3000 \mathrm{~g}$ for $5 \mathrm{~min}$ and subsequently washed in cold wash medium (Invitrogen). The hepatocytes obtained were cultured in a medium composed of three parts $\alpha$-minimum essential medium and one part endothelial cell basal medium-1 (3:1; Lonza, Basel, Switzerland) supplemented with L-glutamine (5 mM), penicillin $(50 \mathrm{IU} / \mathrm{ml})$, streptomycin $(50 \mathrm{~g} / \mathrm{ml})$ (all from Sigma-Aldrich, St. Louis, MO, USA), and 10\% fetal calf serum (FCS; Invitrogen). After a few days of culture ASS1-HLSC clones were expanded and subsequently frozen. Wild-type HLSCs were isolated from cryopreserved normal human hepatocytes $(\mathrm{hH})$ obtained from Cambrex Bio Science, Verviers S.p.r.l. (Verviers, Belgium). hH were also used as normal control of mature hepatocytes. 
Isolation of HLSC-derived EVs (HLSC-EVs)

Briefly, $2 \times 10^{6}$ HLSCs and shRNA ASS1 knockdown HLSCs (HLSC shRNA-ASS1) were cultured in serumfree Roswell Park Memorial Institute (RPMI) medium for $18 \mathrm{~h}$ at $37{ }^{\circ} \mathrm{C}$. The supernatant was centrifuged for $20 \mathrm{~min}$ at $3000 \mathrm{~g}$ to remove cell debris and apoptotic bodies. This was followed by a two-step ultracentrifugation protocol whereby the supernatant was firstly centrifuged at $10,000 \mathrm{~g}(10 \mathrm{~K})$ for $1 \mathrm{~h}$ at $4{ }^{\circ} \mathrm{C}$ to pellet the $10 \mathrm{~K} \mathrm{EV}$ fraction and then a second ultracentrifugation at $100,000 \mathrm{~g}(100 \mathrm{~K})$ for $1 \mathrm{~h}$ at $4{ }^{\circ} \mathrm{C}$ to isolate the $100 \mathrm{~K}$ EV fraction (Beckman Coulter Optima L-90 K, Fullerton, CA, USA) [19]. Both the $10 \mathrm{~K}$ and $100 \mathrm{~K}$ fractions were resuspended in RPMI supplemented with $1 \%$ dimethyl sulfoxide (DMSO) and frozen at $-80{ }^{\circ} \mathrm{C}$ for later use. The viability of HLSCs at the time of EV collection was 97-99\% as determined by trypan blue exclusion.

As suggested by Kowal et al. [20], an iodixanol (Optiprep from Sigma-Aldrich) floating separation protocol was used to further purify the EV fractions from free floating contaminating proteins and RNAs [21]. Briefly, the pellets of EVs obtained after differential ultracentrifugation were directly resuspended in $500 \mu \mathrm{l} 60 \%$ iodixanol (Optiprep from Sigma-Aldrich) mixed with $0.25 \mathrm{M}$ sucrose and transferred to ultracentrifuge tubes (10.4-ml polycarbonate centrifuge bottles; Beckman Instruments). Subsequent gradients of iodixanol at $30 \%, 15 \%$, and $5 \%$ were then layered on top of the initial $60 \% \mathrm{EV}$ iodixanol/sucrose preparation and the final volume adjusted to $10 \mathrm{ml}$ by topping up with saline solution. The tubes were then ultracentrifuged at $350,000 \mathrm{~g}$ for $1 \mathrm{~h}, 4^{\circ}$ $\mathrm{C}$, without braking in an Optima L-100 K ultracentrifuge (Beckman Coulter) equipped with type 90Ti rotor. Following ultracentrifugation, the 15\%,30\%, and 60\% fractions were recovered, diluted with phosphate-buffered saline (PBS), and ultracentrifuged again at 100,000 g for $1 \mathrm{~h}$. The pellet obtained was resuspended in RPMI supplemented with $1 \%$ DMSO and either used fresh or stored for subsequent studies under $-80{ }^{\circ} \mathrm{C}$ conditions. No difference in biological activity was observed between fresh and stored EVs.

In order to study the internalization of EVs by fluorescent microscopy, EVs were labeled with $1 \mu \mathrm{M}$ Dil dye (Thermo Fisher Scientific, Waltham, MA,USA) as described previously [18]. Briefly, purified EVs were resuspended in PBS supplemented with $1 \mu \mathrm{M}$ Dil dye and ultracentrifuged at $100,000 \mathrm{~g}$ for $1 \mathrm{~h}$ at $4{ }^{\circ} \mathrm{C}$. Following labeling, the EVs were washed once more with PBS by ultracentrifugation as mentioned above. The pellet obtained was then resuspended in RPMI with 1\% DMSO and frozen for subsequent studies.

Concentration and size distribution of EVs were determined by the Nanosight LM10 system (NanoSight, Wiltshire, UK). Briefly, EV preparations were diluted (1:200) in sterile saline solution and analyzed by the Nanoparticle Analysis System using the NTA 1.4 Analytical Software [21].

\section{Flow cytometric analysis}

Cytofluorometric analysis was performed as described previously [4]. The antibodies used (conjugated with phycoerythrin (PE) or fluorescein isothiocyanate (FITC)) are as follows: anti-CD45, anti-Albumin, anti-CD90, anti-CD73, anti-CD105, anti-CD29, anti-CD31, antiKDR, and anti-VE-Cadherin (Dako Denmark A/S, Copenhagen, Denmark). All incubations with antibodies were performed in $100 \mu \mathrm{l}$ PBS containing $0.1 \%$ bovine serum albumin (BSA) at $4{ }^{\circ} \mathrm{C}$. The cells were washed twice between incubations and analyzed (10,000 cells/ sample) on a BD FACSCalibur cytometer (BD Biosciences Pharmingen, San Jose, CA, USA). For detection of albumin, cells were permeabilized and labeled with antialbumin monoclonal antibody (R\&D Systems, Abington, UK) followed by PE-conjugated anti-mouse IgG secondary antibody. All samples were gated on the basis of negative controls, and compensated appropriately prior to analyses. Population percentages and numbers were generated for gated populations from each experiment using Cell Quest software (BD Biosciences Pharmingen).

\section{In vitro osteogenic, adipogenic, and endothelial differentiation}

Osteogenic, adipogenic, and endothelial differentiation of ASS1-HLSCs was performed as described previously [4]. Briefly, ASS1-HLSCs were cultured in osteogenesis induction medium (Lonza) for 3 weeks (replenished twice per week for 3 weeks). Differentiation was evaluated by fixing cells with $4 \%$ paraformaldehyde for 20 min and then staining with alizarin red, $\mathrm{pH} 4.1$ (Sigma-Aldrich), at room temperature. For adipogenic differentiation, cells were cultured in adipogenesis induction medium (Lonza), followed by adipogenic maintenance medium (Lonza). To evaluate the differentiation, cells were fixed with $4 \%$ paraformaldehyde for $20 \mathrm{~min}$ at room temperature then stained with $0.5 \%$ oil red O (Sigma-Aldrich) in methanol (Sigma-Aldrich). Endothelial cell differentiation was obtained by culturing ASS1-HLSCs in EBM (Lonza) with vascular endothelial growth factor (10 ng/ml; Sigma-Aldrich) for 10 days. Following culture, endothelial differentiation was evaluated by flow cytometric analyses of endothelial markers as described previously [4].

\section{Immunofluorescence analysis}

Indirect immunofluorescence of cells was performed as described previously [4]. Briefly, ASS1-HLSCs cultured on chamber slides (Nalge Nunc International, Rochester, NY, USA) were fixed with $4 \%$ paraformaldehyde and/or permeabilized (only for intracellular markers) with $0.1 \%$ 
Triton X-100 buffer. Cells were then labeled with the following monoclonal antibodies: anti-albumin (R\&D Systems), anti-nestin (BD Biosciences Pharmingen), anti$\alpha$-fetoprotein ( $\alpha$ FP; R\&D Systems), anti-nanog (Abcam, Cambridge, MA), anti-Sox2 (Abcam), anti-vimentin (Sigma-Aldrich), anti-cytokeratin 8 (CK8), anti-CK19, anti-Von Willebrand factor (all from Sigma-Aldrich), and anti-ASS1 (Thermo Fisher Scientific). Alexa Fluor 488 anti-rabbit IgG and Texas Red anti-mouse IgG (Thermo Fisher Scientific) were used as secondary antibodies and Hoechst 33258 dye (Sigma-Aldrich) was applied for nuclear staining. Labeling of cells with only secondary antibodies or substitution with nonimmune rabbit, rat, or mouse IgGs served as controls. Slides were analyzed by confocal microscopy using a Zeiss LSM 5 Pascal Model Confocal Microscope (Carl Zeiss International, Jena, Germany).

\section{In vitro culture in RCCS and urea production}

In order to differentiate HLSCs and ASS1-HLSCs into functional hepatocytes, cells were cultured in microgravity conditions using the Rotary Cell Culture System (RCCS; Synthecon Incorporated, Houston, TX, USA) as described previously [4]. Briefly, cells $(250,000 / \mathrm{ml})$ were resuspended in medium consisting of 75\% Dulbecco's modified Eagle's medium (DMEM; Mediatech, Herndon, VA, USA), and 25\% MCDB 201 (Sigma-Aldrich) supplemented with 2\% fetal bovine serum (FBS), linoleic acid (Sigma-Aldrich), Lascorbic acid (Sigma-Aldrich), insulin-transferrin-selenium (ITS; Sigma-Aldrich), penicillin $(100 \mu \mathrm{g} / \mathrm{ml})$, streptomycin $(100 \mu \mathrm{g} / \mathrm{ml})$, and $10 \mathrm{ng} / \mathrm{ml}$ of hepatocyte growth factor and fibroblast growth factor 4; $10 \mathrm{ml}$ of the cell suspension was then loaded into circular RCCS vessels and rotated about their own axis at 8-10 rotations per minute under $37{ }^{\circ} \mathrm{C}$ conditions. After 4 days of culture, the supernatant was collected, centrifuged at $300 \mathrm{~g}$ for $5 \mathrm{~min}$ and stored at $-20^{\circ} \mathrm{C}$. Levels of urea in the supernatants were then evaluated using the blood urea nitrogen (BUN) colorimetric detection kit as per the manufacturer's protocol (Arbor assays, MI, USA). For selective RCCS experiments, cells were cultured in the presence of HLSC-EVs with or without $\alpha$-methyl-DL-aspartic acid (MDLA), a specific inhibitor of ASS1 enzyme. Treatment of ASS1-HLSCs with ASS1 shRNA EVs or fibroblast EVs (hFib EV) served as controls.

\section{Western blot analysis}

The level of ASS1 enzyme in cells was determined by Western blot analyses. Briefly, cells were lysed on ice for $30 \mathrm{~min}$ in radioimmunoprecipitation assay (RIPA) buffer (50 mM Tris-HCl PH 7.4, $150 \mathrm{mM} \mathrm{NaCl,} \mathrm{1 \%} \mathrm{NP-40,}$ $0.1 \%$ SDS; Sigma-Aldrich) supplemented with the protease inhibitors phenylmethylsulfonyl fluoride (PMSF) (1 mM), leupeptin $(10 \mu \mathrm{g} / \mathrm{ml})$, and aprotinin (100 units/ $\mathrm{ml})$. Proteins from EVs were isolated using the all-in-one purification kit (Norgen Biotek Corp, TO, Canada) according to the manufacturer's protocol, and the concentrations determined by the Bradford method.

Protein samples at a concentration of 10-30 $\mu \mathrm{g}$ were separated in $8 \%$ or $4-15 \%$ gradient SDS-PAGE gels under reducing conditions and electroblotted onto $0.2-\mathrm{mm}$ nitrocellulose membranes (GE Healthcare Life Sciences, MA, USA). The membranes were blocked in Trisbuffered saline-Tween (TBS-T; $25 \mathrm{mM}$ Tris, $\mathrm{pH}$ 8.0, $150 \mathrm{mM} \mathrm{NaCl}$, and $0.05 \%$ Tween-20) containing 5\% (w/v) nonfat dried milk for $1 \mathrm{~h}$. After blocking, membranes were probed overnight with mouse anti-ASS1 (BD Transduction Laboratories), mouse anti-CD63, rabbit anti-tubulin, and goat anti-actin (Santa Cruz Biotechnology, CA, USA). After extensive washings with TBS-T, the blots were incubated with appropriate peroxidase conjugated secondary antibodies (goat anti-mouse, goat anti-rabbit, and mouse anti-goat IgG; Pierce, Thermo Fisher Scientific) for $1 \mathrm{~h}$ at room temperature. Following incubation, the membranes were washed extensively with TBS-T, probed with enhanced Super Signal West Femto Maximum Sensitivity Substrate (Thermo Fisher Scientific), and detected by the Chemidoc system (Bio-rad, CA, USA).

\section{Immunoprecipitation and enzymatic activity of ASS1}

Cells were lysed in nondenaturing lysis buffer $(137 \mathrm{mM}$ $\mathrm{NaCl}, 2 \mathrm{mM}$ EDTA, 20 mM Tris- $\mathrm{HCl}, \mathrm{pH}$ 7.5, 10\% glycerol, $1 \%$ Nonidet P-40, and protease inhibitor cocktail) and centrifuged at $300 \mathrm{~g}$ for $15 \mathrm{~min}$ at $4{ }^{\circ} \mathrm{C}$. The supernatants were collected and quantified for total protein concentration using the Bio-Rad protein assay method.

Immunoprecipitation of ASS1 was performed using Dynabeads Protein G (Thermo Fisher Scientific). Briefly, the beads were incubated with $10 \mu \mathrm{g}$ ASS1-antibody (Thermo Fisher Scientific) per mg of total protein for $1.5 \mathrm{~h}$ at $4{ }^{\circ} \mathrm{C}$ to form complexes. The bead/ASS1-antibody complexes were washed with PBS-0.02\% tween and incubated with cell lysates (1 mg total protein) overnight at $4{ }^{\circ} \mathrm{C}$ under rotation. After three washes with PBS$0.02 \%$ tween, ASS1 proteins were eluted by adding $20 \mu \mathrm{l}$ $50 \mathrm{mM}$ glycine at $\mathrm{pH} 2.8$. In order to prevent the loss of the tridimensional structure of ASS1, $200 \mu \mathrm{l}$ TRIS-HCL $20 \mathrm{mM}$ pH 7.8 was added.

Eluted proteins were then evaluated for ASS1 activity using a modified version of the assay described by Lakhal-Naouar et al. [22]. Briefly, eluted protein samples (12.5 $\mu$ l per reaction) were resuspended in reaction buffer (20 mM Tris-HCl, pH 7.8, 4 mM ATP, 4 mM citrulline, $4 \mathrm{mM}$ aspartate, $6 \mathrm{mM} \mathrm{MgCl} 2,20 \mathrm{mM} \mathrm{KCl}$, and 0.2 units of pyrophosphatase) to a final volume of $20 \mu \mathrm{l}$. The reaction samples were then transferred to 96-well microtiter plates in duplicates and incubated for $30 \mathrm{~min}$ at $37{ }^{\circ} \mathrm{C}$. Following incubation the reaction was stopped by adding $20 \mu \mathrm{l}$ malachite green reagent (Malachite 
Green Phosphate Assay Kit, Bioassay System, CA, USA). Reactions without citrulline and aspartate substrates were prepared to serve as controls. Phosphate accumulation was determined at $655 \mathrm{~nm}$ by spectrophotometry, and the concentration interpolated from a standard curve of inorganic phosphate (Pi). Due to the spontaneous release of $\mathrm{Pi}$ in the absence of substrates, the final concentration of Pi from affinity-purified proteins and/ or rat liver extract (RLE; served as positive control for the reaction) were determined by subtracting the mean concentration of Pi obtained in the absence of substrates from the mean concentration of Pi obtained in the presence of substrates. The specific ASS1 activity was determined using the following formula: nanomoles of phosphates released/mg protein/30 $\mathrm{min}$ [22]. In selected experiments, ASS1-siRNA transfected ASS1-HLSC were used.

\section{RNA extraction and qRT-PCR}

Total RNA from cells was extracted using TRIzol reagent (Thermo Fisher Scientific) and total RNA from HLSC-EVs was isolated using the all-in-one purification kit (Norgen Biotek Corp.) according to the manufacturer's protocol. The quantity and quality of isolated RNAs were determined using the Nanodrop ND-1000 spectrophotometer (Thermo Fisher Scientific). cDNA was then synthesized using the High Capacity cDNA Reverse Transcription Kit (Thermo Fisher Scientific) as per the manufacturer's protocol. cDNA at a concentration of 2 ng was used per sample per quantitative real-time polymerase chain reaction (qRT-PCR) reaction in triplicate using a 96-well StepOne Real-Time System (Thermo Fisher Scientific). Wells containing only primers were cycled in parallel with each run and served as negative cDNA controls. For mRNA expression in cells, results were analyzed using the RQ method with GUSB gene as an internal control and for HLSC-EVs, the $2^{-\Delta C t}$ method was adopted using S18 gene as internal control. Primers and probes were designed using the Universal ProbeLibrary Assay Design Center software (www. lifescience.roche.com). Primers used to amplify ASS1 mRNAs are summarized in Table 1.

\section{ASS1 silencing}

A set of five pLKO.1 HIV-based lentiviral vectors targeting the human ASS1 gene were purchased (TRCN0000045553, TRCN0000045554, TRCN0000045555, TRCN0000045556, TRCN0000045557; Dharmacon RNAi Consortium (TRC) Lentiviral shRNA). shRNAs were tested on HLSCs to evaluate the silencing efficiency and the most efficient and stable shRNA was used to specifically downregulate ASS1 expression in HLSCs. The lentiviruses pLKO.1-scr (expressing a "scramble" shRNA as control) and pLKO.1ASS1 (expressing the shRNA specific for ASS1) were
Table 1 Primers used in qRT-PCR to evaluate ASS1 mRNA expression

\begin{tabular}{ll}
\hline PCR primers & Primer sequences (5'-3') \\
\hline hASS1-Iso1 & F1 TGT GAA AAC AGA TTC CACG C \\
& R1 CCA ATG TTG GCC AGA TAG GC \\
hASS1-Iso2 & F1 ACG CTA TGT CCA GCA AAG GC \\
& R1 CCA ATG TTG GCC AGA TAG GC \\
hASS1-Exon 14 (Primer 1) & F AAGTCCCAGGAGCGAGTGG \\
hASS1-Exon 15 (Primer 2) & $\mathbf{R}$ GTGGGGCACCTACCTCACC \\
& $\mathbf{F}$ GCCAGGCTGAGCTGACAAG \\
& $\mathbf{R}$ ACCTGGAGGCTCTGAAGC
\end{tabular}

ASS argininosuccinate synthase, $F$ forward, $q R T-P C R$ quantitative real-time polymerase chain reaction, $R$ reverse

produced in HEK293FT cells using a lentiviral packaging system after which HLSCs were infected with the lentiviruses in the presence of Sequa-brene (Sigma-Aldrich). Following infection, cells were selected with $5 \mu \mathrm{g} / \mathrm{ml}$ puromycin. The efficacy and stability of silencing in selected cells was evaluated by qRT-PCR.

\section{siRNA transfection}

ASS-siRNA and nonsilencing siRNA were purchased from Thermo Fisher Scientific. Transient transfection of ASS-siRNA was performed using Lipofectamine RNAiMAX transfection reagent (Invitrogen) as per the manufacturer's protocol. ASS1-HLSCs (500,000 cells per well) were seeded in a petri dish $(10-\mathrm{cm}$ diameter) and cultured for $24 \mathrm{~h}$. The complete culture medium was replaced with antibiotic-free medium and transfected with 300 pM ASS-siRNA or nonsilencing RNA for 3 days in the presence of Lipofectamine RNAiMAX. Before the addition in cell cultures, siRNAs were incubated with lipofectamine for $20 \mathrm{~min}$ at room temperature in Opti-Mem medium (Invitrogen). Preliminary experiments using FITCsiRNA (Qiagen, Valencia, CA, USA) indicated that the peak of expression was 3 days after transfection. After 3 days of transfection, ASS1-HLSCs were detached with trypsin and $3.0 \times 10^{6}$ cells were cultured in RCCSs in the presence of $1 \times 10^{10}$ EV-HLSCs. The effective ASS-siRNA transfection was evaluated in ASS1-HLSCs by RT-PCR. ASS enzymatic activity was measured after 4 days of culture under RCCS culture conditions.

\section{DNA mutation analysis}

Genomic DNA was extracted using DNeasy Blood \& Tissue Kit (Qiagen) according to the manufacturer's instructions. The quality and quantity of extracted DNA was determined using the Nanodrop ND-1000 spectrophotometer (NanoDrop Technology). 
Table 2 SNaPshot primers

\begin{tabular}{ll}
\hline SNaPshot primers & SNaPshot primer sequences \\
\hline R363W & $T_{20}$ GGTGTACATCCTCGGC \\
G390R & $T_{30}$ GCCAACTGATGCCACC \\
\hline
\end{tabular}

R363W was used to amplify the genomic region containing the codon mutation g.55277 C > T and primer G390R for the region containing the mutation g.59839 G > A
Two regions of the human ASS1 gene located in exons 14 and 15 were amplified by PCR. These regions comprise of the following codon mutations: R363W (exon 14) and G390R (exon 15). The primers were developed (Table 2) based on the GenBank reference sequence (accession no. NC_000009.11), using Primer Express 3.0 software (Thermo Fisher Scientific). PCR was then performed in a final volume of $50 \mu \mathrm{l}$, containing $10 \times \mathrm{PCR}$ buffer, 0.05 units/ $\mu \mathrm{l}$ JumpStart Taq polymerase, $10 \mathrm{mM}$ deoxynucleotide triphosphates mix, $150 \mathrm{ng}$ genomic DNA, and $500 \mathrm{nM}$ primers. Cycling conditions were as follows: 1 min at $94{ }^{\circ} \mathrm{C}, 35$ cycles at: $94{ }^{\circ} \mathrm{C}$ for $30 \mathrm{~s}, 62{ }^{\circ} \mathrm{C}$
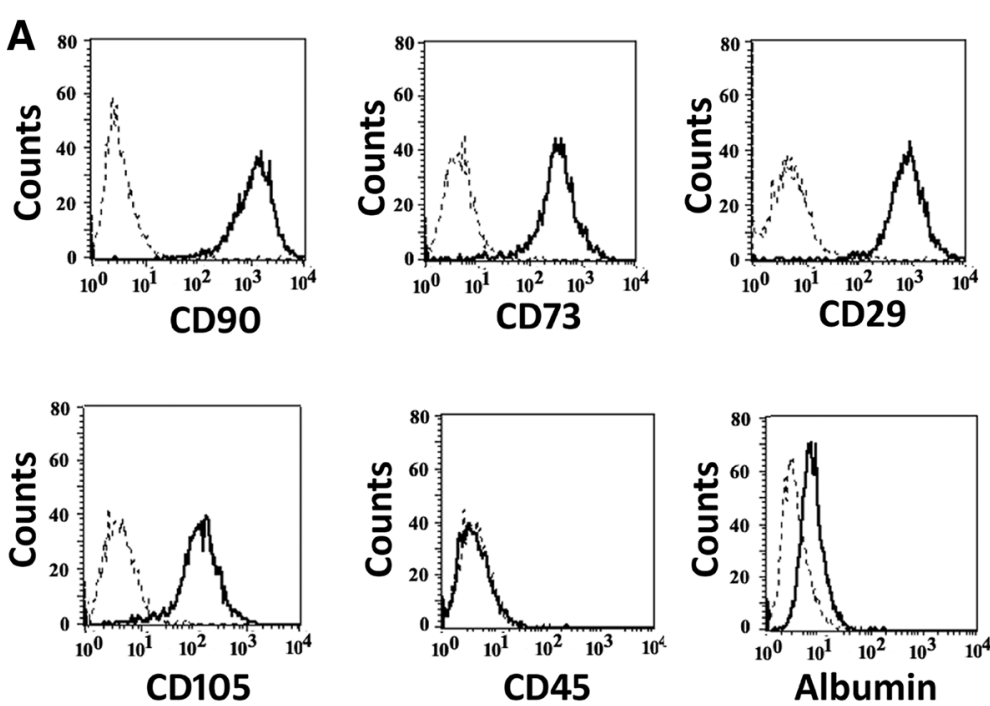

B
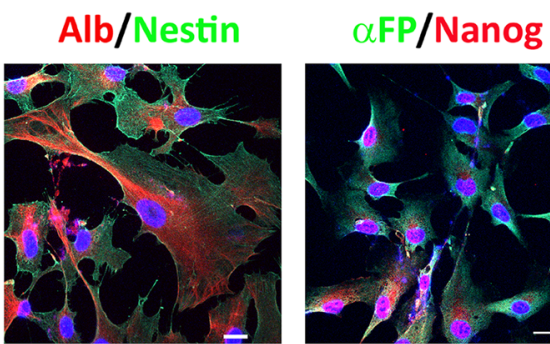

Albumin

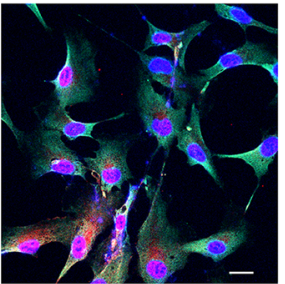

Sox 2

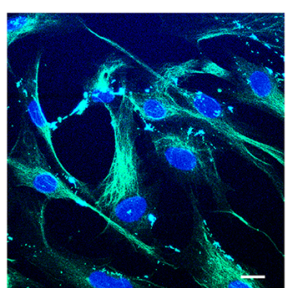

Vimentin

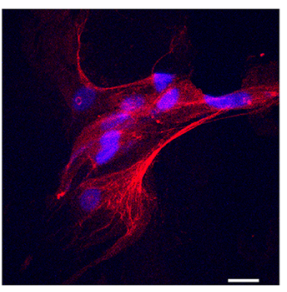

CK8
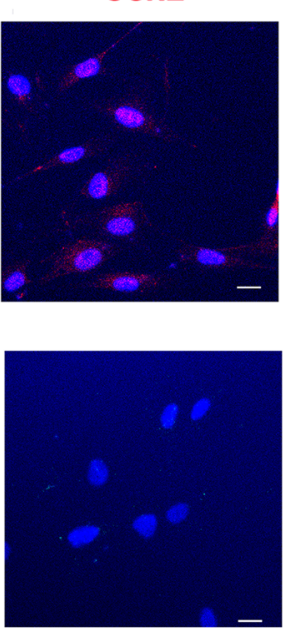

СК19

Fig. 1 Characterization of ASS1-HLSCS. a Representative flow cytometric analysis of markers expressed by ASS1-HLSC (black histograms; dotted histograms represent the isotypic controls). Cells were labeled with FITC- or PE-conjugated antibody. One hundred percent of ASS1-HLSCS were positive for CD90, CD73, CD29, and CD105, and negative for CD45 as described previously for normal HLSCs [4]. ASS1-HLSCs were also positive for the liver marker albumin [4]. Data represent one of three experiments with similar results. b Representative immunofluorescence micrographs of ASS1-HLSCs stained with antibodies against albumin, nestin, a-fetoprotein (a-FP), nanog, sox2, vimentin, cytokeratin (CK)8 and CK19. Hoechst dye 33258 was applied for nuclei staining. Scale bars $=5 \mu \mathrm{m}$. Data represent one of three experiments with similar results 
for $30 \mathrm{~s}$, and $72{ }^{\circ} \mathrm{C}$ for $60 \mathrm{~s}$, followed by $1 \mathrm{~min}$ at $72{ }^{\circ} \mathrm{C}$. At the end of the reaction, $10 \mu \mathrm{l}$ PCR-amplified DNA samples were analyzed using $1 \%$ agarose gel.

To evaluate the presence of DNA in EVs derived from HLSCs, DNA was extracted and analyzed by PCR. Briefly, 14 different preparations of EVs obtained from HLSCs were pooled together by ultracentrifugation at $100,000 \mathrm{~g}$ for $2 \mathrm{~h}$ at $4{ }^{\circ} \mathrm{C}$. The supernatant was discarded and lysis buffer was added directly to the EV pellet and processed as per the manufacturer's protocol to isolate the DNA (DNeasy Blood \& Tissue Kit, Qiagen). Exons 14 and 15 of the hASS1 gene were amplified using PCR as described above and amplicons were analyzed using $1 \%$ agarose gel.

PCR products from ASS1-HLSCs and ASS1-HLSCs treated with HLSC-EVs were analyzed for mutations (c.1087C $>$ T and c.168G $>$ A) using the ABI PRISM SNaPshot Multiplex Kit (Thermo Fisher Scientific), according to the protocol supplied by the manufacturer (normal HLSCs served as control). The SNaPshot method is based on the dideoxy single-base extension of unlabeled oligonucleotide primers. For each of the two mutations analyzed above, a primer annealing adjacent to the potentially mutant nucleotide was developed (Table 2). Briefly, the SNaPshot reaction was performed in a volume of $10 \mu \mathrm{l}$, containing $3 \mu \mathrm{l}$ PCR product, $5 \mu \mathrm{l}$ ready reaction mix, $1 \times$ sequencing buffer, and $\mathrm{SNaPshot}$ primers concentrated at $0.02 \mathrm{pmol} / \mu \mathrm{l}$. At the end of the reaction, the labeled products were first treated with shrimp alkaline phosphatase (SAP; USB Corporation) to remove excess dideoxynucleotide triphosphate and then separated on 36- $\mathrm{cm}$-long capillaries by performing a 25 -min run in an automatic sequencer (ABI PRISM 3500 Genetic Analyzer, Thermo Fisher Scientific). GeneScan Analysis Software version 3.7 (Thermo Fisher Scientific) was used for data analysis. For each sample, the intensity of the fluorescent peak was measured.

\section{A}
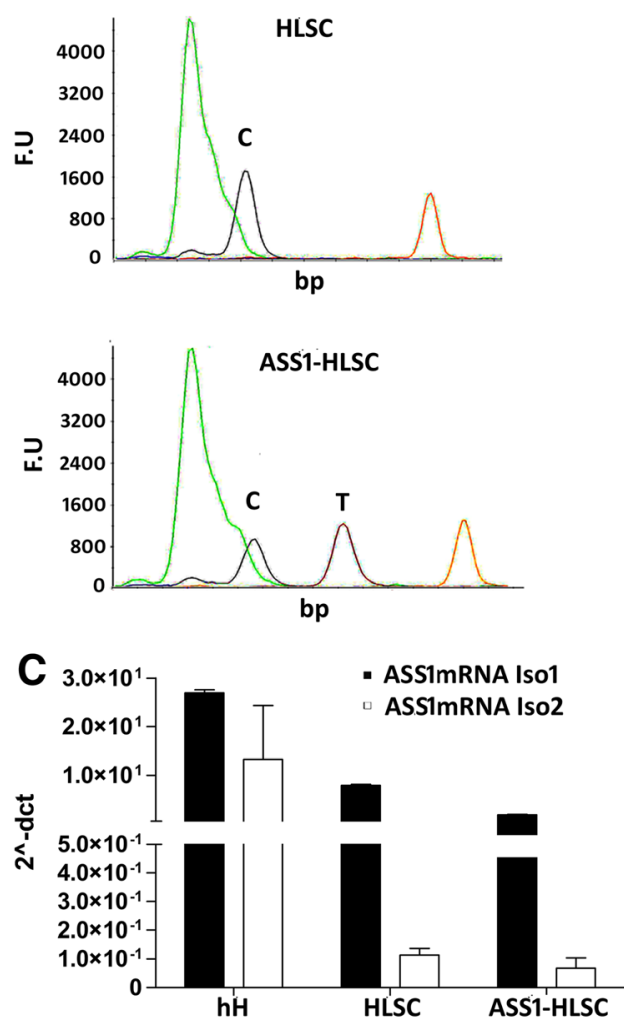
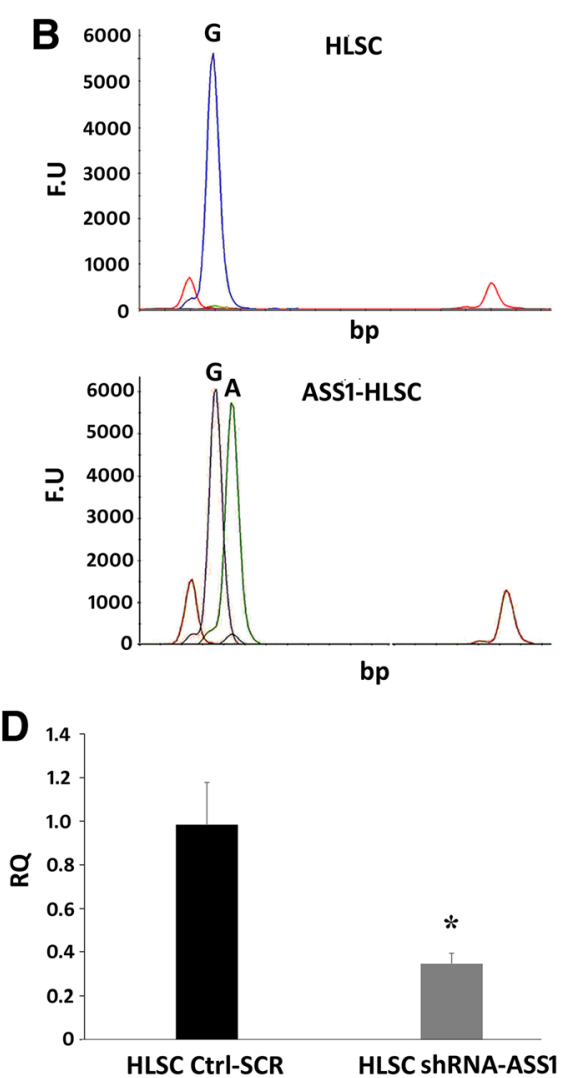

Fig. 2 The expression of ASS1 gene and ASS1 mRNA in HLSCS and ASS1-HLSC. a,b Representative SNaPshot sequences of ASS1 gene in normal human liver stem cells (HLSCS) and HLSCS from the liver of a patient suffering from citrullinemia type 1 (ASS1-HLSCS). a The upper electropherogram shows a normal ASS1 gene profile from HLSCs; the lower electropherogram shows the mutated gene profile from ASS1-HLSCS (C.1087C > T). b The upper electropherogram shows a normal ASS1 gene profile; the lower electropherogram shows the mutated ASS1-HLSC gene profile (c.168G > A). Data represent one of three experiments with similar results. c qRT-PCR analysis showing the expression of ASS1 isoforms 1 (Iso 1) and 2 (Iso2) mRNA in human hepatocytes $(\mathrm{hH}), \mathrm{HLSCS}$, and ASS1-HLSCs. hH were used as positive control. $\mathbf{d}$ qRT-PCR analysis of ASS1 Iso 1 mRNA in HLSCs transfected with ASS1 shRNA. Data represent the mean of two independent experiments performed in triplicate. ${ }^{*} p<0.05$, HLSC shRNA-ASS1 vS HLSC Ctrl-SCR. A adenine, C cytosine, F.U fluorescence unit, G guanine, SCR scramble, T thymine 


\section{Statistical analysis}

Results are expressed as mean \pm standard deviation (SD). Statistical analysis was performed using the Student's $t$ test and analysis of variance (ANOVA) with NewmannKeuls test or ANOVA with Dunnet's multicomparison tests where appropriate. A $p$ value $<0.05$ was considered significant.

\section{Results}

\section{Characterization and in vitro differentiation of} citrullinemia type I-derived ASS1-HLSCs

ASS1-HLSCs derived from the liver of a patient with citrullinemia type I were characterized to confirm their expression of stem cell markers similar to HLSCs. Flow cytometric analysis revealed that ASS1-HLSCs, like their normal counterparts, were positive for several mesenchymal stem cell markers such as CD90, CD73, CD29, and CD105 (Fig. 1a). Furthermore, they were positive for the liver tissue-specific marker albumin but negative for the hematopoietic marker CD45 (Fig. 1a). In addition, immunofluorescence microscopy confirmed ASS1-HLSCs to be positive for the hepatocyte precursor marker $\alpha$-FP, as well as vimentin (100\%), nestin (100\%), and CK8 (40\%) (Fig. 1b). In contrast, CK19, a marker for oval cells, was negative (Fig. 1b). To assess the in vitro differentiation capabilities of ASS1-HLSCs, they were induced to differentiate into endothelial, osteogenic, and adipogenic lineages. Similar to HLSCs, ASS1-HLSCs were able to undergo endothelial differentiation when cultured in endothelial induction medium (Additional file 1: Figure S1). After 3 weeks in culture, ASS1-HLSCs compared to undifferentiated cells expressed de novo endothelial markers such as KDR, CD31, VE-cadherin, and von Willebrand Factor (vWF). Furthermore, when cultured in osteogenic differentiation medium, ASS1-HLSCs transformed morphologically from spindle shaped cells to cuboidal cells and underwent mineralization as reflected by alizarin staining (Additional file 1: Figure S1). ASS1HLSCs when maintained in adipogenic differentiation medium did not differentiate into adipocytes as was also observed with normal HLSCs (data not shown).

In order to identify and characterize the ASS1 mutations in ASS1-HLSCs, a SNaPshot sequencing analysis was implemented. Briefly, after DNA extraction, a first amplification step was performed using two different specific primers for the genomic regions of the ASS1 gene expressing two potential codon mutations (g.55277 C> T, g.59839 G > A). The PCR products were then analyzed for mutations using the $A B I$ PRISM SNaPshot Multiplex Kit. As shown in Fig. 2a and $b$, the mutations in ASS1-HLSCs were confirmed by the presence of the mutated bases $\mathrm{T}$ and $\mathrm{A}$ which were absent in normal HLSCs. At variance to mature $\mathrm{hH}$ that expressed both isoform 1 and 2 of ASS1

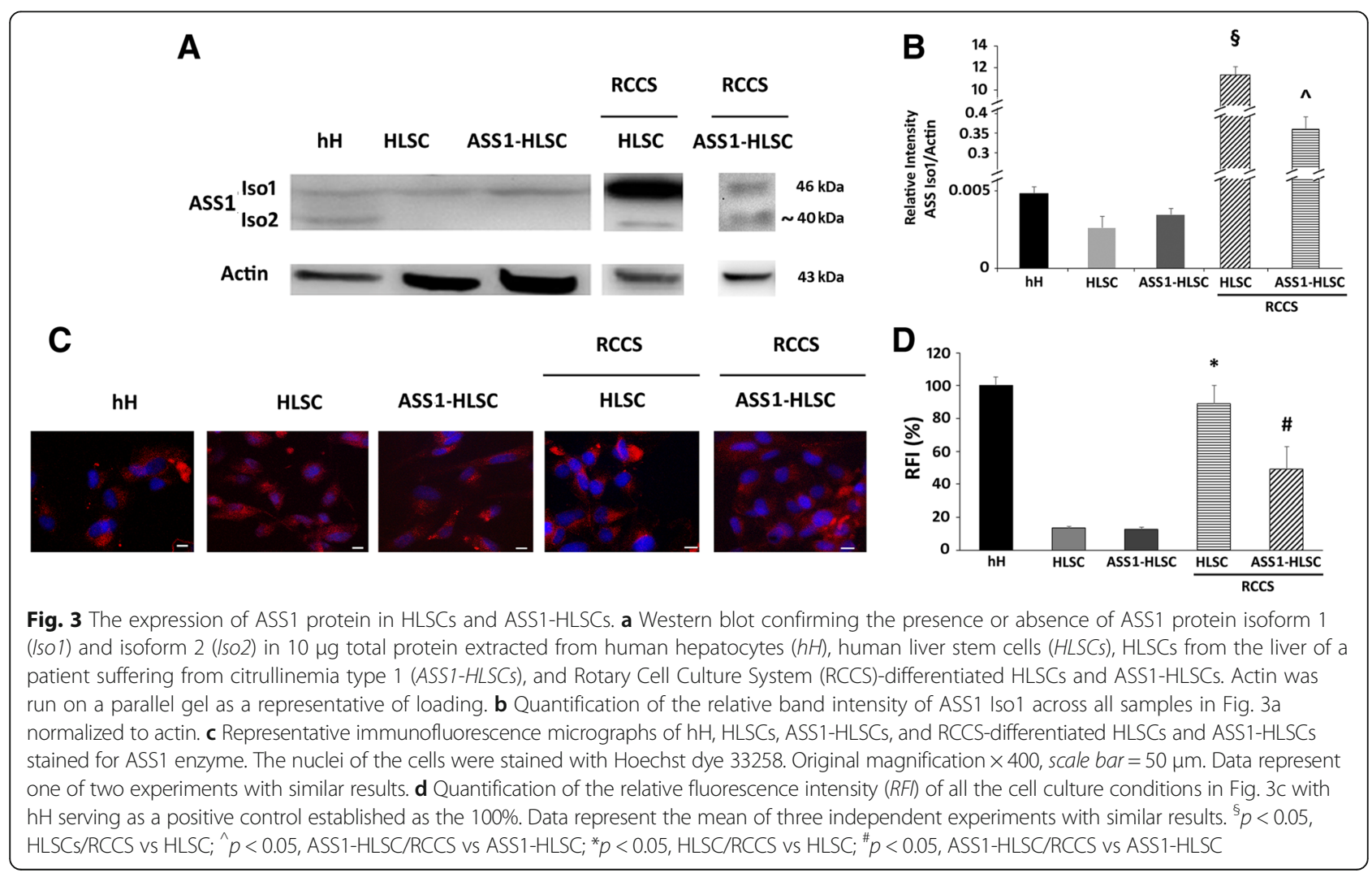


mRNA, the undifferentiated HLSCs and ASS1-HLSCs expressed mainly isoform 1 (Fig. 2c). Figure 2d shows the reduction of ASS1 mRNA expression in HLSCs silenced for the ASS1 gene.

\section{Expression of ASS1 protein}

The expression of ASS1 protein in mature hH, HLSCs, and ASS1-HLSCs was evaluated by Western blot (Fig. 3a and b). $\mathrm{hH}$ expressed two isoforms of ASS1 protein, one
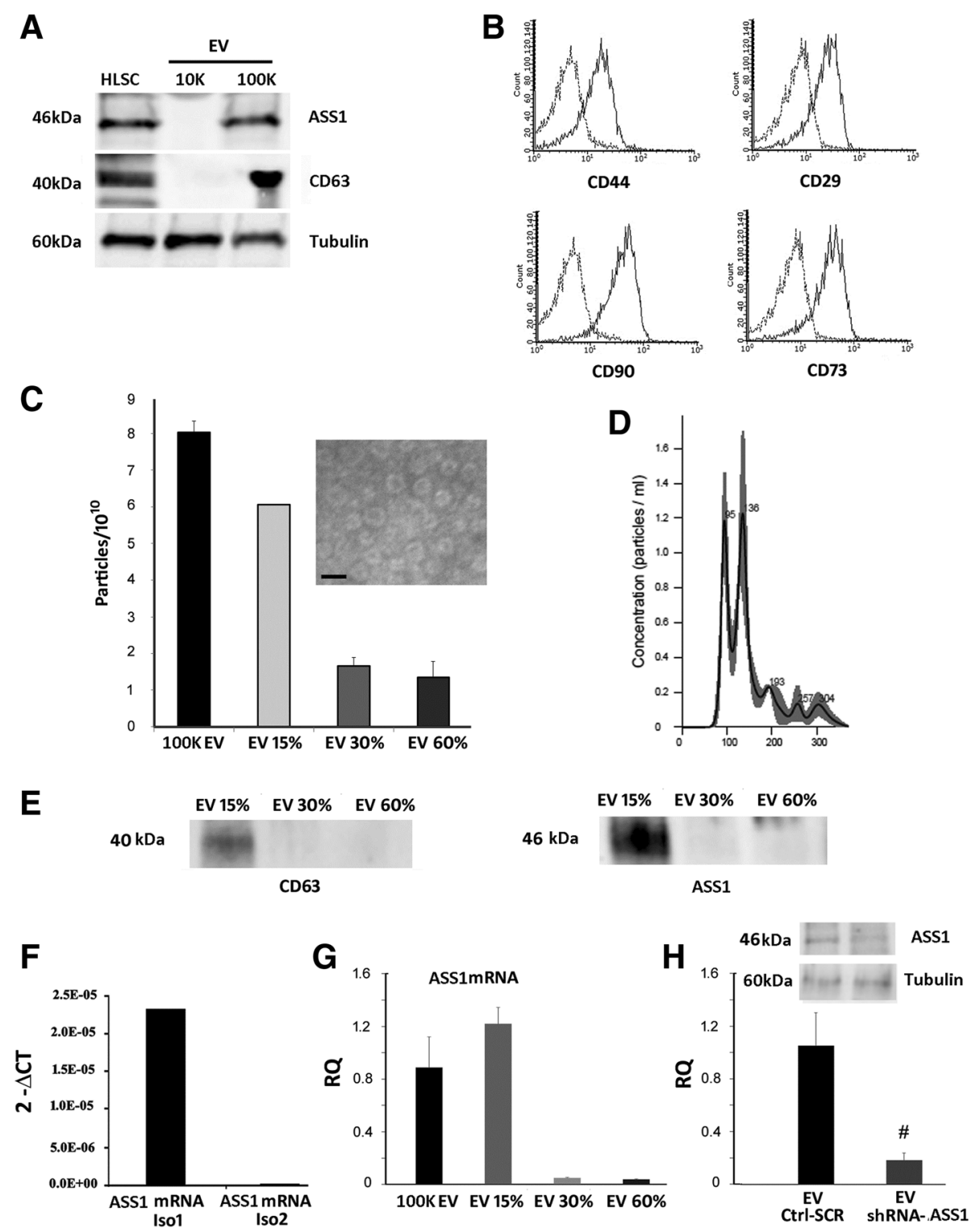

Fig. 4 Characterization of HLSC-derived EVs. a Representative Western blot analysis of ASS1 and CD63 expression in human liver stem cells (HLSCS) and the $10 \mathrm{~K}$ and $100 \mathrm{~K}$ fractions of HLSC-derived extracellular vesicles (EVs) obtained by differential ultracentrifugation. Tubulin was run on a parallel gel as a representative of loading $(10 \mu \mathrm{g}$ protein). Data represent one of two experiments with similar results. b Flow cytometric analysis of mesenchymal stem cell markers expressed by the $100 \mathrm{~K}$ fraction of HLSC-EVs. The $10 \mathrm{~K}$ fraction also expresses mesenchymal stem cell markers (data not shown). Data represent one of two experiments with similar results. c NanoSight quantification of HLSC-EVs obtained from the $100 \mathrm{~K}$ fraction before and after floating separation on iodixanol gradients (data represent a mean of three different experiments). Insert: representative electron microscopy of $100 \mathrm{~K}$ fraction of HLSC-EVs (scale bar $=100 \mathrm{~nm}$ ). $\mathbf{d}$ NanoSight size distribution graph showing the quantity and size of HLSC-EVs obtained from the 15\% iodixanol gradient. e Representative Western blot analysis of CD63 and ASS1 protein expression in HLSC-EVs isolated from different iodixanol fractions. Data represent one of two experiments with similar results. $\mathbf{f}$ Expression levels of ASS1 isofrom 1 (Iso 1) and isoform 2 (Iso2) mRNA in $100 \mathrm{~K} \mathrm{HLSC-EVs.} \mathbf{g}$ Expression levels of ASS1 Iso1 mRNA in EVs isolated from different iodixanol fractions. h ASS1 mRNA Iso1 expression in EVs derived from ASS1 shRNA transfected HLSCs compared with EVs derived from HLSCs transfected with the scramble (SCR). Insert: representative Western blot analysis of ASS1 protein expression in EVs isolated from shRNA transfected HLSCs (EV shRNA-ASS1) and from EVs isolated from HLSCs transfected with the scramble shRNA (EV Ctrl-SCR). Data represent the mean of three independent experiments performed in triplicate. ${ }^{\#} p<0.05$, EV shRNA-ASS1 vs EV Ctrl-ASS1 
at $46 \mathrm{kDa}$ (isoform 1 (Iso1)) and the other at $40 \mathrm{kDa}$ (isoform 2 (Iso2)) (Fig. 3a). Consistent with the low expression of Iso2 mRNA in undifferentiated HLSCs and ASS1-HLSCs, Western blot analysis showed only Iso1. This suggests that under undifferentiating conditions the low amount of Iso2 mRNA was not translated into protein. However, differentiation into hepatocytes via RCCS induced the expression of the Iso2 for both HLSCs and ASS1-HLSCs (Fig. 3a). Moreover, after differentiation the expression of Iso1 was increased in both HLSCs and ASS1-HLSCs compared to the undifferentiated counterparts (Fig. 3a and b).

The expression of the ASS1 protein in hH, HLSCs, and ASS1-HLSCs was further confirmed by immunofluorescence staining (Fig. 3c). As seen in Fig. 3d, quantitative analysis of ASS1 protein expression shows a significant increase after RCCS-induced differentiation (Fig. 3c and d). These data therefore confirm that differentiation to hepatocytes of both the wild-type and mutated HLSCs significantly increases the expression of the ASS1 protein.

\section{Characterization of HLSC-EVs}

On analyzing the $10 \mathrm{~K}$ and $100 \mathrm{~K}$ fractions, ASS1 protein expression was observed only in the $100 \mathrm{~K}$ fraction concurrently with the expression of the exosomal marker CD63 (Fig. 4a). Furthermore, the same fraction was also positive for the mesenchymal markers typical of HLSCs as observed by fluorescence-activated cell sorting (FACS) analysis (Fig. 4b). No further analysis was performed on the $10 \mathrm{~K}$ fraction as it was negative for ASS1 and CD63 (Fig. 4a).

The $100 \mathrm{~K}$ fraction was also submitted to floating separation whereby $75 \%$ of the EVs were detected in the $15 \%$ iodixanol fraction with a mean size of $155 \pm 3.6 \mathrm{~nm}$ as determined by NanoSight analysis (Fig. 4c and d). In addition, transmission electron microscopy revealed a homogenous layer of these vesicles with a morphology resembling exosomes with a smaller size than observed by NanoSight (Fig. 4c, insert). Furthermore, on analyzing the EVs obtained from the three iodixanol fractions by Western blot, only the $15 \%$ fraction was positive for the exosomal marker CD63 as well as the ASS1 protein (Fig. 4e).

PCR analysis also confirmed at a molecular level the presence of mRNA for ASS1 Iso1 but not for ASS1 Iso2 in $100 \mathrm{~K} \mathrm{HLSC-EVs} \mathrm{(Fig.} \mathrm{4f)} \mathrm{and} \mathrm{in} \mathrm{the} \mathrm{15 \%} \mathrm{iodixanol}$ EV fraction compared to the other fractions (Fig. 4g).

In order to evaluate whether restoration of ASS1 enzymatic activity was observed in ASS1-HLSCs treated with HLSC-EVs, we generated EVs depleted of the ASS1 enzyme by silencing the gene at a cellular level. As shown in Fig. 4h, EVs derived from HLSC shRNA-ASS1 were depleted of both Iso1 ASS1 mRNA and protein.

\section{EVs derived from normal HLSCs increased urea production} and ASS1 enzymatic activity in mutated ASS1-HLSCs

As shown in Fig. 5, HLSC-EVs were internalized in ASS1-HLSCs after $6 \mathrm{~h}$ of incubation at $37{ }^{\circ} \mathrm{C}$. It has been described that, as a consequence of the genetic mutations, the ASS1 enzyme activity is decreased in

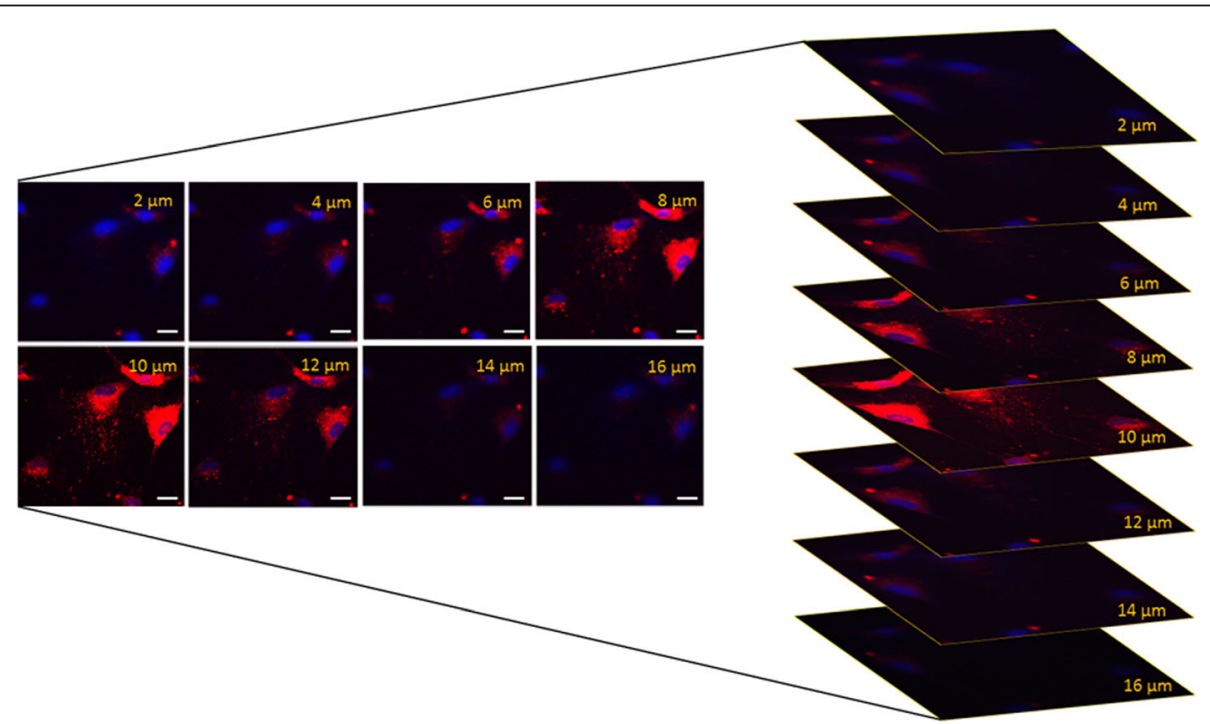

Fig. 5 Internalization of HLSC-EVs in hepatocytes differentiated from ASS1-HLSCs. Representative confocal microscopy showing the internalization of $1 \times 10^{10}$ Dil-labeled EVs in hepatocytes differentiated from ASS1-HLSCs after $6 \mathrm{~h}$ of incubation at $37^{\circ} \mathrm{C}$. Z stack analysis shows the presence of EVs within the cytoplasm of the cells indicating an effective uptake of vesicles; scale bar $=50 \mu \mathrm{m}$. Data represent one of three experiments performed with similar results 
fibroblasts, liver, and in all ASS1-expressing tissues [2]. In order to evaluate whether HLSC-EVs were able to correct the defective urea production and enzymatic activity in ASS1-HLSCs, ASS1-HLSCs were treated with HLSC-EVs $\left(1 \times 10^{10}\right.$ particles $)$ in RCCS for 4 days. At the end of the experiments, urea production and ASS enzymatic activity were measured (Fig. 6a and b). Mutated ASS1-HLSCs produced significantly less urea and showed a decreased ASS1 enzymatic activity than normal HLSCs. HLSC-EV treatment significantly increased urea

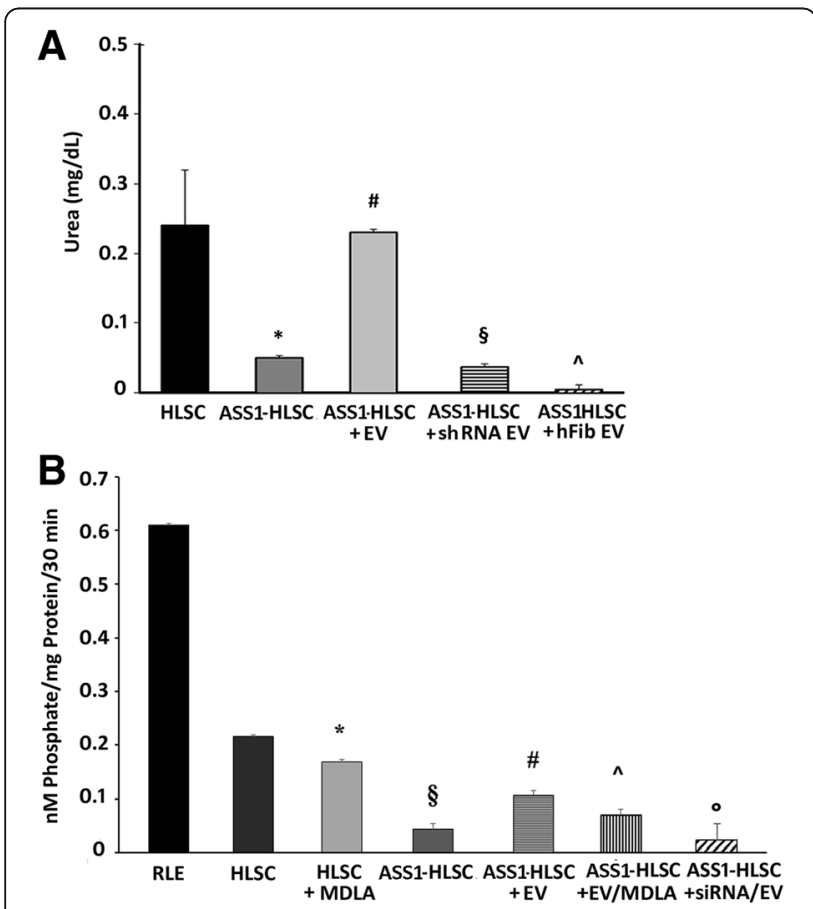

Fig. 6 Urea production and ASS1 enzymatic activity. a Histogram representing the urea production ability of hepatocytes differentiated under RCCS conditions for 4 days from human liver stem cells (HLSCS), HLSCs from the liver of a patient suffering from citrullinemia type 1 (ASS1-HLSCS), ASS1-HLSCS treated with $1 \times 10^{10} \mathrm{HLSC}$-derived extracellular vesicles (EVS), ASS1-HLSCs treated with $1 \times 10^{10} \mathrm{HLSC}-\mathrm{EV}$ s from ASS1 shRNA transfected HLSCs (shRNA EVS) or with $1 \times 10^{10} \mathrm{EV}$ s derived from human fibroblasts ( $h F i b$ EV). Data are expressed as mean \pm SD of four different experiments. ANOVA with Newmann-Keuls multicomparison tests was performed. ${ }^{*} p<0.05$, ASS1-HLSC vs HLSC; ${ }^{*} p<0.05$, ASS1$\mathrm{HLSC}+\mathrm{HLSC}-\mathrm{EV}$ s vs ASS1-HLSC; ${ }^{\$} p<0.05$, ASS1-HLSC + shRNA EVs vs ASS1-HLSC + HLSC-EVs; ${ }^{\wedge} p<0.05$ ASS1-HLSC + hFib EVs vs AS-HLSC + EVs. $\mathbf{b}$ The enzymatic activity of ASS1 immunoprecipitated from either rat liver extract (RLE; positive control), hepatocytes differentiated in RCCS for 4 days from HLSCS, ASS1-HLSCS, or ASS1-HLSCS treated with $1 \times 10^{10} \mathrm{HLSC}-E V$ s were measured. For selected experiments the enzyme activity was measured in the presence of a-methyl-DL-aspartic acid (MDLA), a specific inhibitor of ASS1 enzymatic activity, and using ASS1-HLSCs previously transfected with ASS-siRNA. Data are expressed as mean \pm SD of four separate experiments. ANOVA with NewmannKeuls multicomparison tests was performed. ${ }^{*} p<0.05$, HLSC + MDLA vs HLSC; ${ }^{\circledR} p<0.05$, ASS1-HLSC vs HLSC; ${ }^{*} p<0.05$, ASS1- HLSC + EVs vs ASS1-HLSC; ${ }^{\wedge} p<0.05$, ASS1- HLSC + EV/MDLA VS ASS1-HLSC + EV; ${ }^{\circ} p<0.05$, ASS1-HLSC + siRNA/EV VS ASS1-HLSC + EV production and enzymatic activity in ASS1-HLSCs. The specificity of the enzymatic activity reaction was confirmed by the inhibitory effect of treating the cells with MDLA as a specific inhibitor of the enzyme (Fig. 6b). ASS1 enzymatic activity was also inhibited in HLSC-EV-treated ASS1HLSCs when the cells were transfected with ASS1-siRNA (Fig. 6b). ASS1 shRNA-depleted HLSC-EVs were unable to restore urea production in ASS1-HLSCs (Fig. 6a). The ability of HLSC-EVs to restore urea production was specific since EVs obtained from human fibroblasts (hFib) which did not contain ASS1 protein and only a low level of ASS1 mRNA (data not shown) were ineffective (Fig. 6a). Moreover, the reduction of ASS1 urea production by EVs derived from hFib also depended on an inhibition of cell differentiation in RCCS (data not shown).

\section{HLSC-EV treatment decreased DNA mutations in ASS1- HLSCs}

Since HLSC-EVs carry fragments of ASS1 DNA (Fig. 7), we evaluated whether they may affect the mutations when incorporated into ASS1-HLSCs. We performed $\mathrm{SNaPshot}$ sequencing to determine the contribution of HLSC-EVs to correction of both mutations present in ASS1-HLSCs. Figure 8 shows that the amplitude of picks of the mutated bases $\mathrm{T}$ and $\mathrm{A}$ belonging to one allele of the ASS1 region of ASS1-HLSCs was significantly reduced when cells were cultured in adhesion culture for 6,24 , and $48 \mathrm{~h}$ with HLSC-EVs $\left(1 \times 10^{10}\right.$ particles $)$.

\section{Discussion}

In the present study we demonstrated that EVs derived from normal HLSCs increased the production of urea and ASS1 enzymatic activity in hepatocytes differentiated from HLSCs derived from a patient with Citrullinemia type I.

Citrullinemia type I is an inherited disorder of the urea cycle caused by a genetic mutation in the ASS1 gene. The absence of a functional form of ASS1 enzyme leads to a rapid accumulation of ammonia and other toxic substances in the blood leading to an early neonatal death. Liver transplantation remains the only curative treatment for this defect. However, due to limited availability of donor livers, substitute therapies are currently being researched [23].

Recently, Syres et al. demonstrated that the accumulation of cysteine in organs was decreased after the injection of mesenchymal stem cells in a cysteinotic knockout mice model $\left(\mathrm{CTNA}^{-/-}\right)$[24]. The cells were found in multiple organs resulting in a $90 \%$ decrease in tissue cysteine levels, leading to the recovery of kidney injury [24]. Nevertheless, the reduction in tissue cysteine levels could not be attributed to mesenchymal stem cell transdifferentiation or fusion with resident CTNA mutated cells. In further studies, to explain the mechanism 


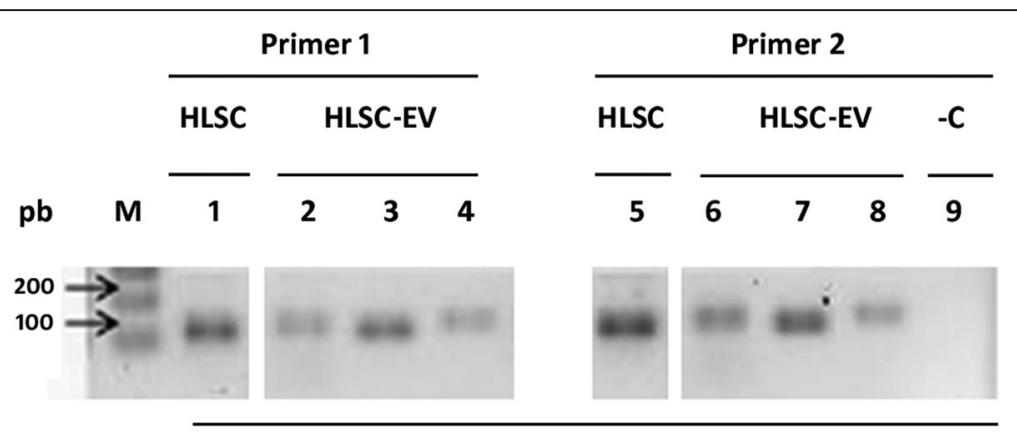

ASS1 Gene

Fig. 7 The expression of the ASS1 gene in HLSCs and EVs. ASS1 gene expression was determined in human liver stem cell-derived extracellular vesicles (HLSC-EVS) by PCR analysis. Two different regions of human ASS1 (CTLN1) gene located in exons 14 and 15 were amplified by PCR with two different primers that amplified both the regions respectively; exon 14 (Primer 1), exon 15 (Primer 2). A PCR without the presence of nucleotides was used as negative control (-C). Three different preparations of EVs (lanes 2, 3, and 4 and lanes 6, 7, and 8) were analyzed in comparison with the cells of origin (HLSCs; lanes 1 and 5)

of reduction of intralysosomal accumulation of cysteine, Iglesias et al. used an in vitro coculture model of $\mathrm{CTNA}^{-1-}$ fibroblasts and human amniotic mesenchymal stem cells [25]. They demonstrated that the uptake of mesenchymal stem cell-derived EVs carrying wildtype cysteinosin protein and mRNA by mutant fibroblasts significantly reduced the lysosomal accumulation of cysteine in the cells. Katsuda et al. recently showed that EVs derived from adipose mesenchymal stem cells may transfer a functional enzyme to target cells [26]. In addition, several studies provided evidence of effective transfer of functional mRNA, miRNA, and DNA by EVs [27-29].

Collectively, these works suggest that EVs could interact with target cells and transfer functional protein and nucleic acids that may modify their phenotype. In agreement with this evidence, we found that HLSC-EVs contained wild-type ASS1 protein, mRNA, and DNA. Furthermore, on incubating these EVs with mutated ASS1-HLSCs the mutated enzymatic effect was corrected, restoring urea production and enzymatic activity. Undifferentiated HLSCs expressed Iso1 and, to a significantly less extent, Iso 2 mRNA, and the amount of Iso2 protein was undetectable by Western blot analysis. Consistently, EVs secreted from undifferentiated HLSCs contained only mRNA and protein of Iso1. In addition, knocking down Iso1 by shRNA in HLSCs depleted the levels of ASS1 mRNA and protein in the EVs released subsequently by the cells. These EVs from ASS1 shRNA knockdown HLSCs were unable to restore urea production in hepatocytes differentiated from ASS1-HLSCs. This result suggests that the biological activity of EVs may depend on the transfer of both functional ASS1 protein and mRNA. It is unclear from this experiment to what extent protein/mRNA transfer contributed to the recovery of ASS1 enzymatic activity in ASS1-HLSCs. However, the result of the experiment using transfection of ASS1-HLSCs with ASS1-siRNA that shows inhibition of HLSC-EVinduced correction of enzymatic activity suggests a predominant role of mRNA transfer.

In addition, we also found that HLSC-EVs carried fragments of the nonmutated ASS1 gene and that the amplitude of the peak of the bases mutated was reduced in ASS1-HLSCs after treatment with vesicles. However, the transfer of DNA was not relevant for the correction of the enzyme activity in ASS1-HLSCs as EVs derived from HLSCs silenced with ASS1 shRNA (which only diminished ASS1 mRNA levels) had a significant reduction in their biological activity.

Further studies are required to evaluate whether the horizontal transfer of DNA could also correct the enzymatic defect in the mutated cells. Nevertheless, several studies have recently investigated the possibility of horizontal transfer of DNA by EVs. For instance, Lázaro-Ibáñez et al. [30] reported the presence of double-stranded genomic DNA fragments in exosomes derived from prostate cancer cells and suggested the transfer of oncogenes between cancer and noncancerous cells. Fischer et al. demonstrated the horizontal transfer of DNA genes by EVs in recipient cells [31]. These studies suggest that vesicles containing genomic DNA may be instrumental in the exchange of genetic information between eukaryotic cells and open the possibility to exploit this mechanism for correction of genetic disorders.

The mechanisms of exosomal biogenesis and sorting of proteins and nucleic acids are only partially known. However, recently the mechanisms controlling specific miRNA sorting in hepatocyte exosomes has been described by Santangelo et al. [32]. They identified an RNA binding protein SYNCRIP as a critical component of miRNA accumulation within exosomes, suggesting a 

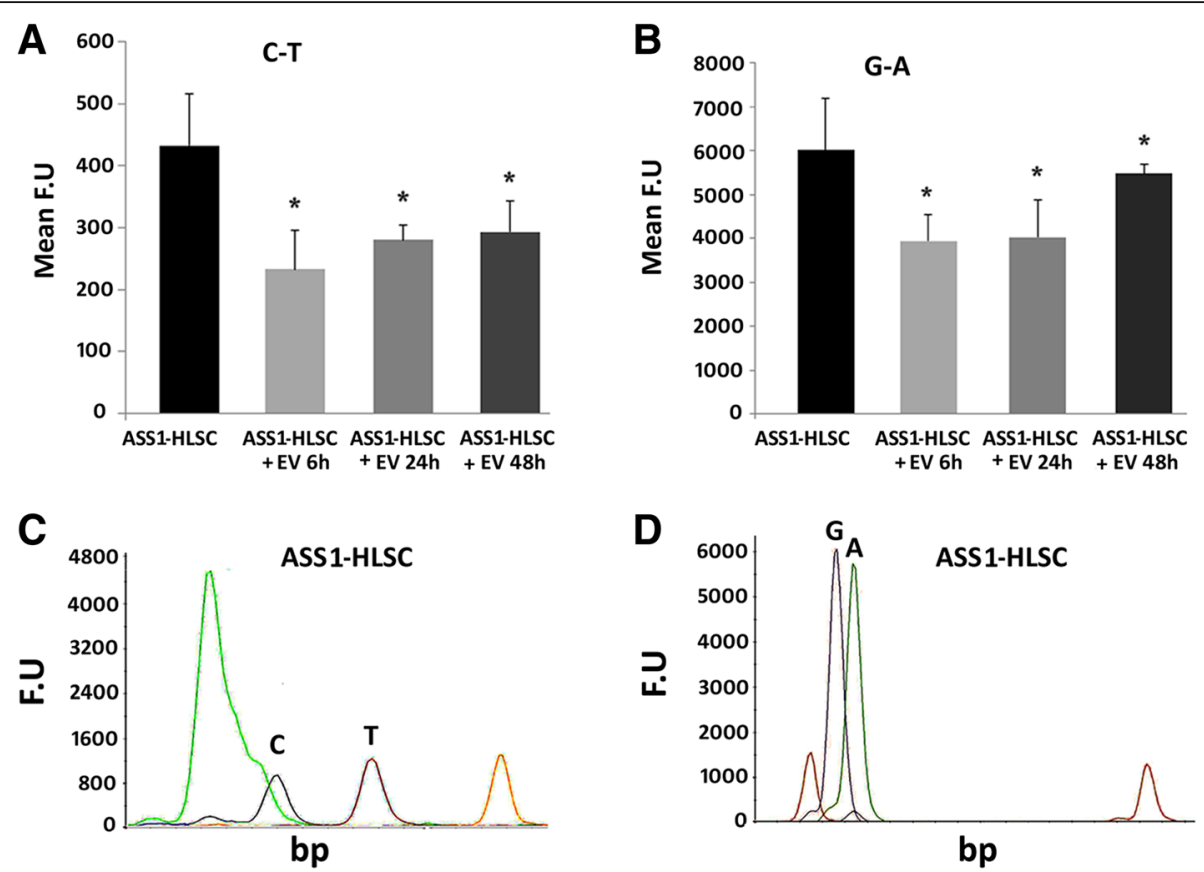

bp
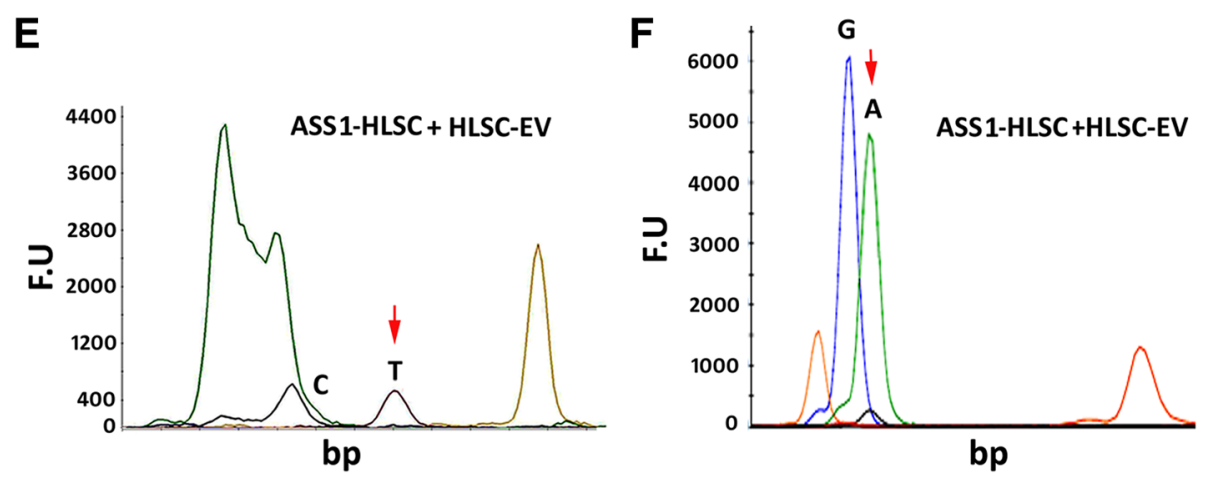

Fig. 8 ASS1 mutations. a,b SNaPshot method was used to characterize the mutations in human liver stem cells (HLSCS) from the liver of a patient suffering from citrullinemia type 1 (ASS1-HLSCS). ASS1-HLSCs were treated with $1 \times 10^{10} \mathrm{HLSC}$-derived extracellular vesicles (EVS) in adherence culture conditions for 6 , 24, and $48 \mathrm{~h}$. At the end of the experiments, DNA was recovered from ASS1-HLSCs treated with or without EVs and sequencing mutation experiments were performed to detect C-T mutations (a) and G-A mutations (b). Data are expressed as mean \pm SD of three individual experiments. ANOVA with Dunet's multicomparison tests was performed. ${ }^{*} p<0.05$, all experimental conditions vs ASS1-HLSC. $\mathbf{c}$-d Representative electropherograms of ASS1-HLSCS performed to detect C-T mutation (c) and G-A mutation (d). e-f Representative electropherograms of ASS1-HLSCS treated for $6 \mathrm{~h}$ with $1 \times 10^{10} \mathrm{HLSC}-\mathrm{EV} \mathrm{s}$ showing the reduction of C-T mutation (e) and G-A mutation (f). A adenine, C cytosine, F.U fluorescence unit, G guanine, $T$ thymine

possible selective modulation of exosome cargo. EVs are enriched in ribonucleoproteins that may be involved in the storage, traffic, and protection of degradation of ribonucleic acid [33]. Moreover, the association of Alix, a component of endosomal sorting complex required for transport, with Ago2, which is involved in miRNA maturation, has been shown to contribute to miRNA accumulation into EVs [34].

\section{Conclusions}

EVs derived from stem cells may act as paracrine mediators by transferring proteins and nucleic acids inducing epigenetic changes in recipient cells. Herein, we found that EVs derived from normal HLSCs have the potential to correct ASS1 enzyme deficiency in hepatocytes differentiated from HLSCs derived from a patient with citrullinemia type I, suggesting a potential application of EVs derived from stem cells in some inherited diseases.

\section{Additional file}

Additional file 1: Figure S1. In vitro differentiation of ASS1-HLSCS. (A) Representative flow cytometric analysis of undifferentiated ASS1-HLSCS showing negative expression of KDR, CD31, and VE-Cadherin. Von Willebrand factor (VWF) expression and alizarin red staining for mineralization was also 
negative in undifferentiated conditions as observed by microscopy. (B) Representative flow cytometric analysis of ASS1-HLSCS after endothelia differentiation showing the presence of KDR, CD31, and VE-Cadherin (black histograms; dotted histograms represent isotypic controls). Representative micrographs showing the expression of VWF in ASS1-HLSCs after endothelial differentiation, and osteogenic differentiation of ASS1-HLSCS showing positive staining for calcium deposits as indicated by alizarin 21 days after culturing in osteogenic differentiation medium. Scale bar $=50 \mu \mathrm{m}$. Data represent one of three experiments performed with similar results. (TIF $8299 \mathrm{~kb}$ )

\section{Abbreviations}

ASS: Argininosuccinate synthase; ASS1-HLSC: Human liver stem cell from the liver of a patient suffering from citrullinemia type I; CK: Cytokeratin; DMSO: Dimethyl sulfoxide; EV: Extracellular vesicle; FACS: Fluorescence-activated cell sorting; FITC: Fluorescein isothiocyanate; hFib: human fibroblasts; hH: Human hepatocytes; HLSC: Human liver stem cell; Iso: Isoform; MDLA: a-Methyl-DL-aspartic acid; PBS: Phosphate-buffered saline; PE: Phycoerythrin; Pi: Inorganic phosphate; qRT-PCR: Quantitative real-time polymerase chain reaction; RCCS: Rotary Cell Culture System; RPMI: Roswell Park Memorial Institute; aFP: a-Fetoprotein

\section{Funding}

This study was supported by Telethon and a grant from Unicyte (Oberdorf NW, Switzerland) to GC

\section{Availability of data and materials}

All data generated or analyzed during the current study are included in this article.

\section{Authors' contributions}

MBHS and SP isolated ASS1-HLSCs, performed hepatocyte differentiation and ASS1 enzymatic activity assays, and contributed towards manuscript writing. $\mathrm{SB}$ and VF analyzed data and contributed towards manuscript writing. MCD performed Western blot analysis and iodixanol floating separation protocol. SK performed experiments, analyzed data, and contributed towards manuscript writing. SP performed ASS1 silencing experiments. ET contributed to the analysis and interpretation of data. RC performed DNA mutation analysis. RC, MSp, and MSa performed the metabolic studies, collected the liver specimen from the Liver Transplantation Centre, and contributed towards data assembly for the study. CT analyzed and interpreted data. GC contributed towards the conception, design, writing, and financial support. All authors read and approved the final manuscript.

\section{Ethics approval and consent to participate}

Human tissue was obtained from the native liver of a 5-year-old patient with neonatal-onset citrullinemia type I undergoing a liver transplant with the written informed consent of the parents. The liver specimen was acquired from the native liver removed for transplantation by the Liver Transplantation Centre according to a local tissue banking protocol (\# 80911) approved by the University of Torino Ethics Board (Comitato Bioetica di Ateneo) and provided anonymously to the researchers.

\section{Consent for publication}

\section{Not applicable.}

\section{Competing interests}

MBHS, MCD, and GC are named as inventors in related patent applications. The remaining authors declare that they have no competing interests.

\section{Publisher's Note}

Springer Nature remains neutral with regard to jurisdictional claims in published maps and institutional affiliations.

\section{Author details}

${ }^{1}$ 2i3T, Società per la gestione dell'incubatore di imprese e per il trasferimento tecnologico, Scarl University of Torino, Torino, Italy. ${ }^{2}$ Molecular Biotechnology Center, University of Torino, Torino, Italy. ${ }^{3}$ Mimetas BV, Leiden, The Netherlands. ${ }^{4}$ Department of Molecular Biotechnology and Health Science, University of Torino, Torino, Italy. ${ }^{5}$ Molecular and Genetic Epidemiology Unit, Human Genetics Foundation, Torino, Italy. ${ }^{6}$ Department of Pediatrics, Regina
Margherita Children's Hospital, University of Torino, Torino, Italy. ${ }^{7}$ Liver Transplantation Center, University of Torino, Torino, Italy. ${ }^{8}$ Unicyte AG, Oberdorf, NW, Switzerland. ${ }^{9}$ Department of Medical Sciences, University of Torino, Corso Dogliotti 14, I-10126 Torino, Italy.

Received: 7 March 2017 Revised: 16 June 2017

Accepted: 10 July 2017 Published online: 27 July 2017

\section{References}

1. Woo HI, Park HD, Lee YW. Molecular genetics of citrullinemia types I and II. Clin Chim Acta. 2014:431:1-8.

2. Vaidyanathan K. Molecular diagnosis of urea cycle disorders: current global scenario. Indian J Biochem Biophys. 2013;50:357-62.

3. Engel K, Hohne W, Haberle J. Mutations and polymorphisms in the human argininosuccinate synthetase (ASS1) gene. Hum Mutat. 2009;30: 300-7.

4. Herrera MB, Bruno S, Buttiglieri S, Tetta C, Gatti S, Deregibus MC, et al. Isolation and characterization of a stem cell population from adult human liver. Stem Cells. 2006;24:2840-50

5. Herrera MB, Fonsato V, Bruno S, Grange C, Gilbo N, Romagnoli R, et al. Human liver stem cells improve liver injury in a model of fulminant liver failure. Hepatology. 2013;57:311-9.

6. Stoltz JF, de Isla N, Li YP, Bensoussan D, Zhang L, Huselstein C, et al. Stem cells and regenerative medicine: myth or reality of the 21th century. Stem Cells Int. 2015;2015:734731

7. Liu S, Zhou J, Zhang X, Liu Y, Chen J, Hu B, et al. Strategies to optimize adult stem cell therapy for tissue regeneration. Int J Mol Sci. 2016;17:E982.

8. Tkach M, Thery C. Communication by extracellular vesicles: where we are and where we need to go. Cell. 2016;164:1226-32.

9. Ratajczak J, Miekus K, Kucia M, Zhang J, Reca R, Dvorak P, et al. Embryonic stem cell-derived microvesicles reprogram hematopoietic progenitors: evidence for horizontal transfer of mRNA and protein delivery. Leukemia. 2006:20:847-56

10. Valadi H, Ekström K, Bossios A, Sjöstrand M, Lee JJ, Lötvall JO. Exosomemediated transfer of mRNAs and microRNAs is a novel mechanism of genetic exchange between cells. Nat Cell Biol. 2007;6:654-9.

11. Deregibus MC, Cantaluppi V, Calogero R, Lo lacono M, Tetta C, Biancone L, et al. Endothelial progenitor cell derived microvesicles activate an angiogenic program in endothelial cells by a horizontal transfer of mRNA. Blood. 2007;110:2440-8.

12. Turturici G, Tinnirello R, Sconzo G, Geraci F. Extracellular membrane vesicles as a mechanism of cell-to-cell communication: advantages and disadvantages. Am J Physiol Cell Physiol. 2014;306:C621-33.

13. Quesenberry PJ, Aliotta J, Deregibus MC, Camussi G. Role of extracellular RNA-carrying vesicles in cell differentiation and reprogramming. Stem Cell Res Ther. 2015;6:153.

14. Bruno S, Grange C, Collino F, Deregibus MC, Cantaluppi V, Biancone L, et al. Microvesicles derived from mesenchymal stem cells enhance survival in a lethal model of acute kidney injury. PLoS One. 2012;7:e33115

15. Gallet R, Dawkins J, Valle J, Simsolo E, de Couto G, Middleton R, et al. Exosomes secreted by cardiosphere-derived cells reduce scarring, attenuate adverse remodelling, and improve function in acute and chronic porcine myocardial infarction. Eur Heart J. 2017;38:201-11.

16. Nojima H, Freeman CM, Schuster RM, Japtok L, Kleuser B, Edwards MJ, et al. Hepatocyte exosomes mediate liver repair and regeneration via sphingosine-1-phosphate. J Hepatol. 2016:64:60-8.

17. Herrera MB, Fonsato V, Gatti S, Deregibus MC, Sordi A, Cantarella D, et al. Human liver stem cell-derived microvesicles accelerate hepatic regeneration in hepatectomized rats. J Cell Mol Med. 2010;14:1605-18.

18. Herrera Sanchez MB, Bruno S, Grange C, Tapparo M, Cantaluppi V, Tetta C, et al. Human liver stem cells and derived extracellular vesicles improve recovery in a murine model of acute kidney injury. Stem Cell Res Ther. 2014; 5:124

19. Théry C, Amigorena S, Raposo G, Clayton A. Isolation and characterization of exosomes from cell culture supernatants and biological fluids. Curr Protoc Cell Biol. 2006;Chapter 3:Unit 3.22.

20. Kowal J, Arras G, Colombo M, Jouve M, Morath JP, Primdal-Bengtson B, et al. Proteomic comparison defines novel markers to characterize heterogeneous populations of extracellular vesicle subtypes. Proc Natl Acad Sci U S A. 2016; 113:E968-77. 
21. Bruno S, Tapparo M, Collino F, Chiabotto G, Deregibus MC, Soares Lindoso $R$, Neri $F$, et al. Renal regenerative potential of different extra-cellular vesicle populations derived from bone marrow mesenchymal stromal cells. Tissue Eng Part A. 2017. doi:10.1089/ten.TEA.2017.0069

22. Lakhal-Naouar I, Jardim A, Strasser R, Luo S, Kozakai Y, Nakhasi HL, et al. Leishmania donovani argininosuccinate synthase is an active enzyme associated with parasite pathogenesis. PLoS Negl Trop Dis. 2012;6:e1849.

23. Lee B, Goss J. Long-term correction of urea cycle disorders. J Pediatr. 2001; 138:S62-71.

24. Syres K, Harrison F, Tadlock M, Jester JV, Simpson J, Roy S, et al. Successful treatment of the murine model of cystinosis using bone marrow cell transplantation. Blood. 2009;114:2542-52.

25. Iglesias DM, El-Kares R, Taranta A, Bellomo F, Emma F, Besouw M, et al. Stem cell microvesicles transfer cystinosin to human cystinotic cells and reduce cystine accumulation in vitro. PLoS One. 2012;7:e42840.

26. Katsuda T, Tsuchiya R, Kosaka N, Yoshioka Y, Takagaki K, Oki K, et al. Human adipose tissue-derived mesenchymal stem cells secrete functional neprilysin-bound exosomes. Sci Rep. 2013;3:1197.

27. Zhou S, Abdouh M, Arena V, Arena M, Arena GO. Reprogramming malignant cancer cells toward a benign phenotype following exposure to human embryonic stem cell microenvironment. PLoS One. 2017;12: e0169899.

28. Jung KO, Youn $\mathrm{H}$, Lee CH, Kang KW, Chung JK. Visualization of exosomemediated miR-210 transfer from hypoxic tumor cells. Oncotarget. 2016;8: 9899-10.

29. Cai J, Wu G, Jose PA, Zeng C. Functional transferred DNA within extracellular vesicles. Exp Cell Res. 2016;349:179-83.

30. Lázaro-Ibáñez E, Sanz-Garcia A, Visakorpi T, Escobedo-Lucea C, Siljander P, Ayuso-Sacido A, et al. Different gDNA content in the subpopulations of prostate cancer extracellular vesicles: apoptotic bodies, microvesicles, and exosomes. Prostate. 2014;74:1379-90.

31. Fischer S, Cornils K, Speiseder T, Badbaran A, Reimer R, Indenbirken D, et al. Indication of horizontal DNA gene transfer by extracellular vesicles. PLoS One. 2016;11:e0163665.

32. Santangelo L, Giurato G, Cicchini C, Montaldo C, Mancone C, Tarallo R, et al. The RNA-binding protein SYNCRIP is a component of the hepatocyte exosomal machinery controlling microRNA sorting. Cell Rep. 2016;17:799-8.

33. Collino F, Deregibus MC, Bruno S, Sterpone L, Aghemo G, Viltono L, et al. Microvesicles derived from adult human bone marrow and tissue specific mesenchymal stem cells shuttle selected pattern of miRNAs. PLoS One. 2010;5:e11803.

34. lavello A, Frech VS, Gai C, Deregibus MC, Quesenberry PJ, Camussi G. Role of Alix in miRNA packaging during extracellular vesicle biogenesis. Int J Mol Med. 2016:37:958-66.

\section{Submit your next manuscript to BioMed Central and we will help you at every step:}

- We accept pre-submission inquiries

- Our selector tool helps you to find the most relevant journal

- We provide round the clock customer support

- Convenient online submission

- Thorough peer review

- Inclusion in PubMed and all major indexing services

- Maximum visibility for your research

Submit your manuscript at www.biomedcentral.com/submit

CBiomed Central 